\title{
Unusual Tumours Hidden in Blind Eyes
}

\author{
Smriti Nagpal Gupta ${ }^{1 \otimes}$, Ruchi Goel $^{\mathbb{1}}$, Ravindra Kumar Saran $^{2}$, Neha Rathie $^{1}$ \\ ${ }^{1}$ Guru Nanak Eye Centre, New Delhi, India \\ ${ }^{2}$ Govind Ballabh Pant Institute of Post Graduate Medical Education and Research (GIPMER), New Delhi, India
}

\begin{abstract}
Introduction: This case report describes 3 cases of unsuspected neoplasms in previously blind eyes, with recent onset pain.

Cases and observations: Case 1: Female with pain, redness in the non-seeing right eye (R/E) for two months. R/E had total cataract, low intraocular pressure and a well-defined globular mass lesion at the posterior pole, seen on ultrasound. Enucleation with an implant was done. Histopathology clinched the diagnosis of choroidal melanoma. Case 2: A 20-year male, developed pain, redness in left eye (L/E) for two months. L/E was blind since childhood, secondary to trauma. The patient underwent enucleation and detailed histopathological examination and immunohistochemistry supported a diagnosis of ependymoma with vascular malformation. Case 3: A 24-year male with pain, redness in L/E for six months, with decrease in size of eyeball. L/E had low vision since childhood. On examination, $\mathrm{L} / \mathrm{E}$ was phthisical with diffuse conjunctival congestion, band-shaped keratopathy, cataract, and neovascularization of iris. Imaging revealed a small distorted globe with highly reflective mass along the posterior pole. Histopathology of the enucleated specimen confirmed the diagnosis of choroidal osteoma, with gliosis of the adjacent RPE.

Conclusion: In the management of a painful blind eye, it is extremely important to rule out an intraocular malignancy, particularly in patients with recent onset of pain.

Key words: Enucleation, Intraocular tumours, Painful blind eye, Occult malignancy.
\end{abstract}

\section{INTRODUCTION}

Enucleation is the definitive treatment of choice in patients with painful blind eyes, especially those unresponsive to topical therapy (Merbs,
2006; Custer \& Reistad, 2000). It has long been known that a phthisical eye may harbor an occult neoplasm (Tripathi et al, 2002; Loeffler et al, 1996; Sarma et al, 1983; Pereira et al, 2006). Vemuganti et al (2001) reported the presence of

$\begin{array}{ll}\text { Financial Interest } \quad: \text { Nil } & \text { Received : 12.08.2020 } \\ \text { Conflict of Interest : Nil } & \text { Accepted : } 01.02 .2021 \\ \text { Corresponding Author } & \\ \text { Dr. Smriti Nagpal Gupta } & \\ \text { Guru Nanak Eye Centre, (Associated with Maulana Azad Medical } \\ \text { College) } \\ \text { New Delhi, India. } \\ \text { E-mail: drsmriting@gmail.com } \\ \text { Contact: +919811140443 }\end{array}$


ocular tumours in almost $50 \%$ of their patients undergoing enucleation. Hence, a thorough preoperative assessment, including imaging, is recommended.

Herein we describe three patients, with preexisting non-seeing eyes, with recent onset of pain. All three underwent enucleation for pain relief, followed by histopathological assessment of the enucleated specimen.

\section{CASE 1}

A 24-year-old female presented with sudden onset, severe pain and redness in Right eye (R/E) for 2 months. R/E had no vision for 3 years, with no history of trauma or surgery. There was no systemic illness. On examination, the left eye (L/E) was within normal limits (WNL) while $\mathrm{R} / \mathrm{E}$ had total cataract with multiple refractile particles in the anterior chamber (AC), and low intraocular pressure (Figure 1a). Imaging showed a classical mushroom shaped, homogenous, well defined globular mass lesion present at the posterior pole, extending into vitreous and causing outward bulging of sclera, with hyper-reflectivities in vitreous cavity (Figure 1b, c). Patient received a short course of steroid therapy to decrease inflammation, followed by enucleation with orbital implant. Histopathology showed tumour involving $>85 \%$ of posterior chamber, extending into scleral lymphatics and optic nerve. Tumour cells contained coarse black melanin pigment, confirming the diagnosis of choroidal melanoma. Optic nerve resection margin was clear of the tumour. Patient received adjuvant radiotherapy, and was symptom free at 1 year follow-up (Figure 1d).
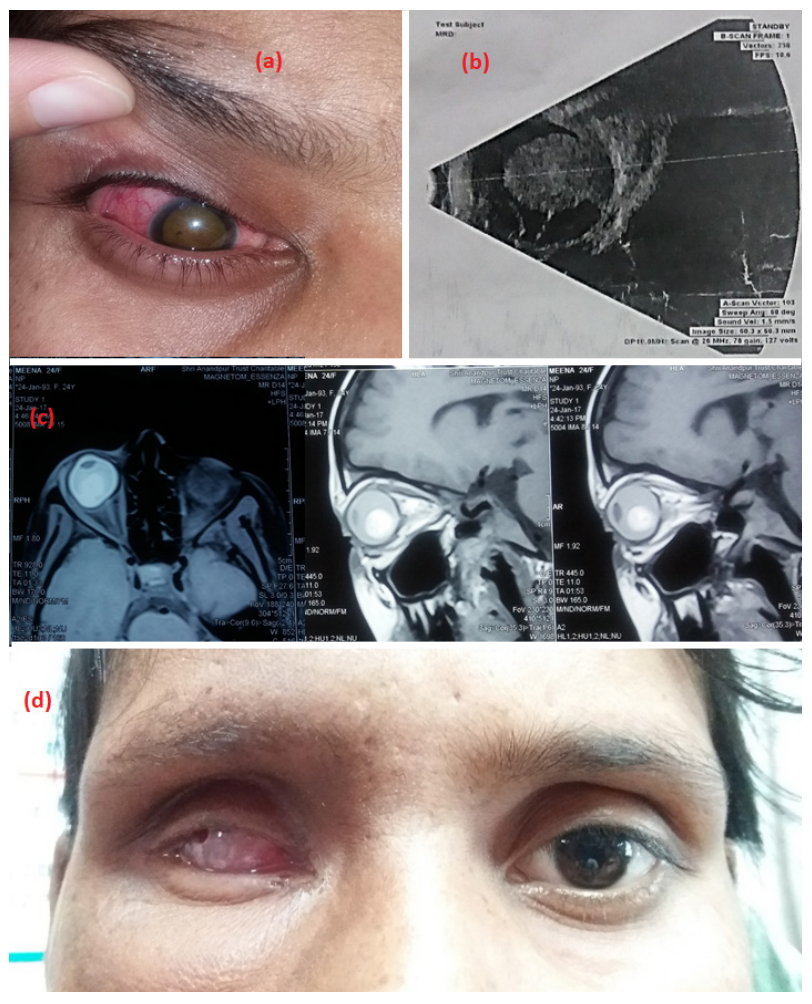

Figure 1: (a) Pre-operative clinical picture of the patient (b) Ultrasound showing the homogenous globular mass (c) Pre-operative MRI picture showing the mass lesion with associated distortion of the globe, axial and sagittal section (d) Postoperative clinical picture of the patient. 


\section{CASE 2}

A 20-year male patient presented with pain, redness in L/E for two months. There was a history of trauma to the L/E during early childhood, followed by gradual loss of vision. On examination, R/E was WNL and L/E had no light perception. L/E had an intercalary staphyloma, neovascular glaucoma, miosed irregular pupil and flat AC. Fundus details were

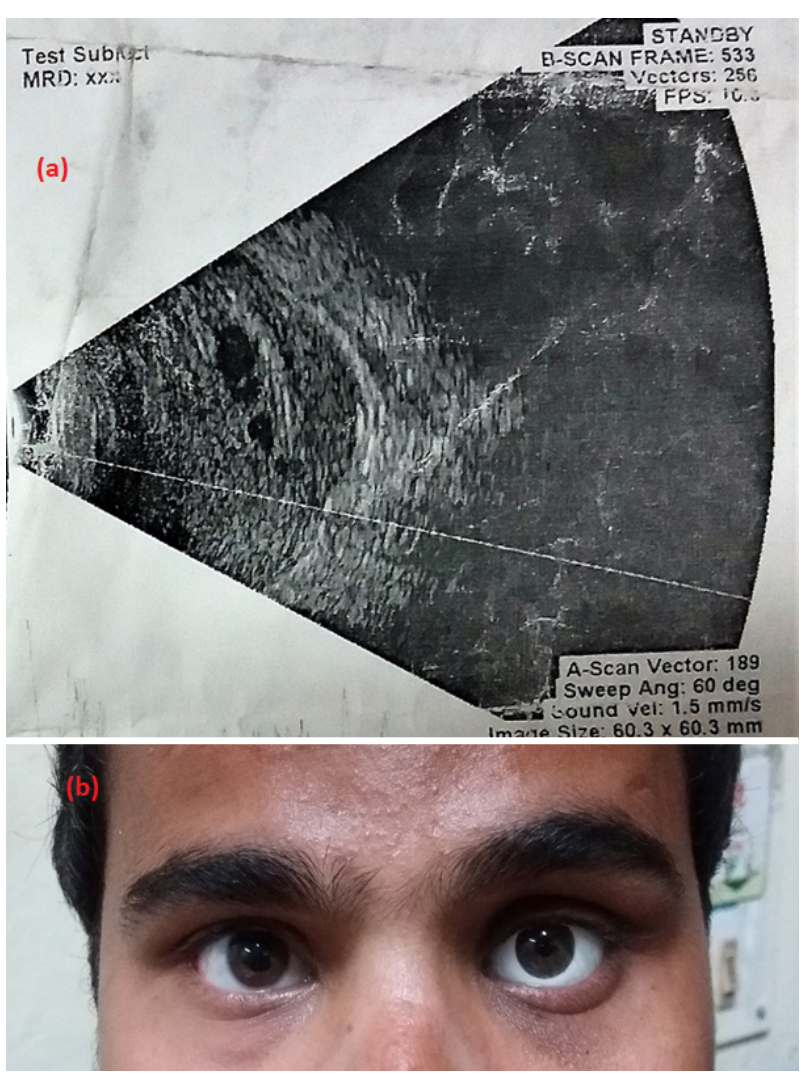

Figure 2: (a) Pre-operative ultrasound showing diffuse hyper-reflective echoes in the vitreous cavity (b) Postoperative clinical picture of the patient with ocular prosthesis in situ. not visualized. Ultrasound showed moderate hyper-reflective echoes in vitreous, suggestive of dispersed vitreous haemorrhage (Figure 2a). Patient underwent enucleation with an implant. Histopathology revealed thinned out cornea and sclera, distorted lens adherent anteriorly to cornea, and staphylomatous distorted uveal tissue. Multiple dilated vessels were identified at the iridocorneal junction and choroid, suggestive of a vascular malformation. Abutting these, was a glial tumour with cellular areas embedded in a fibrillary matrix with areas of hemorrhage and calcification. Tumor cells infiltrated the choroid. Normal layers of retina and optic nerve couldn't be identified. Histology and immunohistochemistry findings were suggestive of an ependymoma with vascular malformation. Postoperative period was unremarkable (Figure 2b). Postoperative MRI did not reveal any recurrence/residual tumor.

\section{CASE 3}

A 24-year-old male presented with pain, redness in $\mathrm{L} / \mathrm{E}$ for 6 months, with decrease in size of the eye. L/E had low vision since childhood. There was no history of trauma/surgery and no systemic illness. On examination, R/E was WNL. L/E was phthisical with no light perception. L/E had diffuse conjunctival congestion, superior intercalary staphyloma, band-shaped keratopathy, complicated cataract, $360^{\circ}$ posterior synechiae and iris 


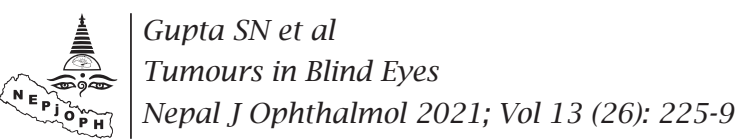

neovascularization, with no view of fundus. Imaging revealed a small distorted globe with a highly reflective, diffuse calcified mass along the posterior pole, extending upto the optic nerve head (Figure 3a). The patient underwent enucleation with an implant (Figure $3 b)$. Histopathology revealed the presence of

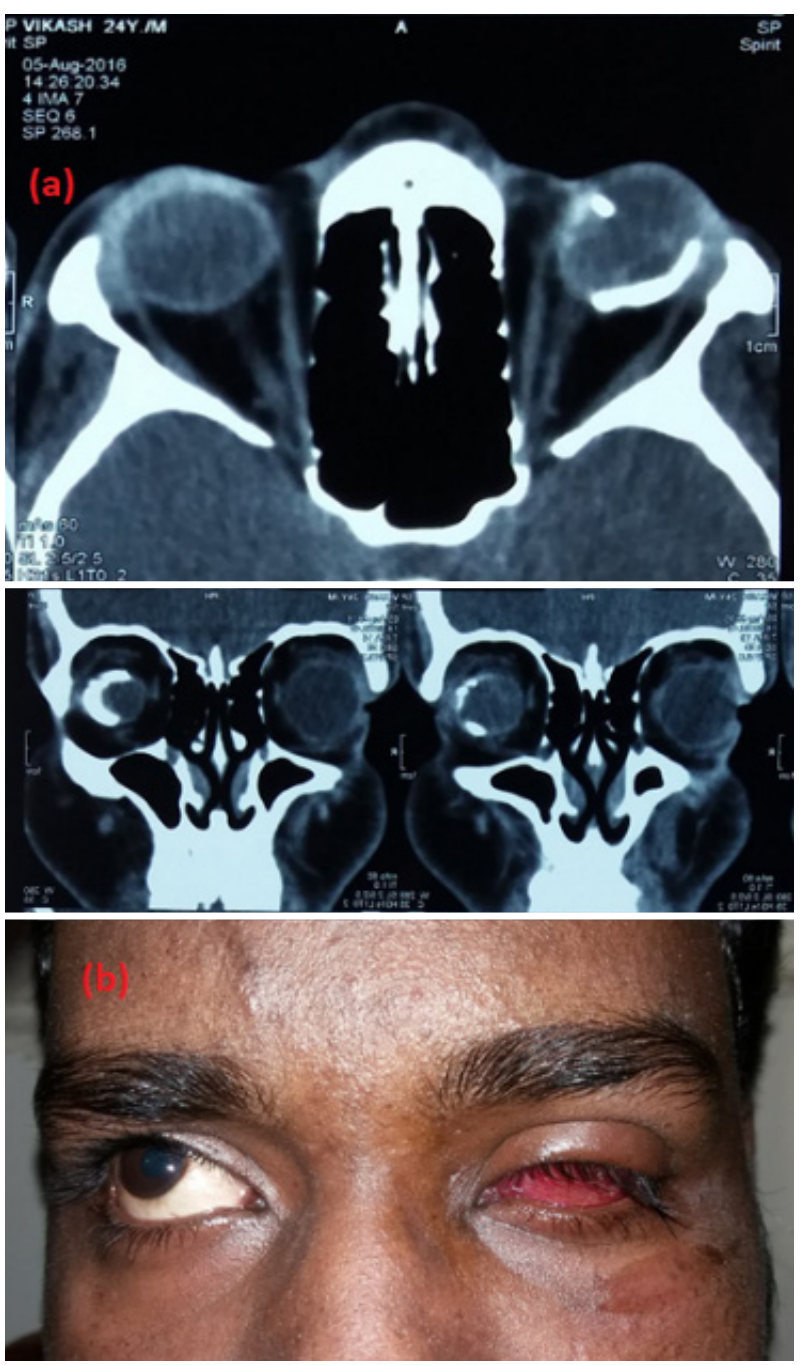

Figure 3: (a) Axial and coronal CT sections, showing phthisical globe with large diffuse calcified mass along the posterior pole (b)

Postoperative clinical picture of the patient. islands of mature cancellous bone, consistent with the diagnosis of choroidal osteoma, with marked gliosis of the adjacent retinal pigment epithelium(RPE). Cut section of the optic nerve was tumour-free. Postoperatively, the socket was healthy with no further complaints at 1year follow-up.

\section{DISCUSSION}

Enucleation is the standard surgical modality for many end-stage ocular diseases. It remains the treatment of choice for pain management in blind eyes, others being topical therapy, retrobulbar alcohol injection or evisceration (Merbs, 2006; Custer \& Reistad, 2000). It is known that blind eyes may harbor occult neoplasms, with past reports of unsuspected intra-ocular malignancy that was diagnosed after enucleation, most common one being malignant melanoma (Tripathi et al, 2002 ; Loeffler et al, 1996 ; Sarma et al, 1983; Pereira et al, 2006; Edelstein et al, 1998). A study in 1976 described 36 such patients with unsuspected malignant melanomas, most of which presented as secondary glaucoma with opaque media (Völcker \& Naumann, 1976), similar to case 1. Retinal ependymomas are extremely rare, with only two other cases described in literature (Hegyi et al, 2005; Tay et al, 2009). Both those had long-standing history with an underlying inciting event, and no tumor suspected pre-operatively, similar to case 2. Choroidal osteomas are rare tumours, classically unilateral, more common in females and with typical CT characteristics (Bryan et 
al, 1983). It is not classically associated with severe ocular inflammation, phthisis or RPE gliosis, which were seen in case 3 .

\section{CONCLUSION}

Hence, we conclude that recent onset of symptoms in a previously blind eye, especially in the absence of any obvious cause for the same, must alert the ophthalmologist to the possibility of a neoplasm. Our study describes the varied clinical presentations of such patients. Pre-operative imaging and histopathological assessment of the enucleated globe must be emphasized.

\section{REFERENCES}

Bryan RN, Lewis RA, Miller SL(1983). Choroidal osteoma. AJNR Am J Neuroradiol;4(3):491-4.

Custer PL, Reistad CE (2000). Enucleation of blind, painful eyes. Ophthal Plast Reconstr Surg;16(5):326-9. doi: 10.1097/00002341-200009000-00004; PMid:11021380

Edelstein C, Shields CL, Shields JA, Eagle RC Jr (1998). Presumed adenocarcinoma of the retinal pigment epithelium in a blind eye with a staphyloma. Arch Ophthalmol;116(4):525-8. doi: 10.1001/archopht.116.4.525; PMid:9565054

Hegyi L, Peston D, Theodorou M, Moss J, Oliver J, Roncaroli F (2005). Primary glial tumor of the retina with features of myxopapillary ependymoma. Am J Surg Pathol;29:1404-9. doi: 10.1097/01.pas.0000172188.02424.d8; PMid:16160486

Loeffler KU, Kivela T, Borgmann H, Witschel H (1996). Malignant tumor of the retinal pigment epithelium with extraocular extension in a phthisical eye. Graefes Arch Clin Exp Ophthalmol;234Suppl 1:S70-5. doi: 10.1007/ BF02343051; PMid:8871153

Merbs SL (2006). Management of a blind painful eye. Ophthalmol Clin North Am;19(2):287-92.

Pereira PR, Odashiro AN, Souza Filho JP, Saraiva VS, Camoriano DG, Burnier MN Jr (2006). Malignancy in the blind painful eye - report of two cases and literature review. Diagn Pathol; 1:45. doi: 10.1186/1746-1596-1-45; PMid:17118184

Sarma DP, Deshotels SJ Jr., Lunseth JH (1983). Malignant melanoma in a blind eye. J Surg Oncol;23:169-72. doi: 10.1002/jso.2930230309; PMid:6345935

Tay A, Scheithauer BW, Cameron JD, Myhre MJ, Boerner MJ (2009). Retinal ependymoma: an immunohistochemical and ultrastructural study. Hum Pathol;40:578-83. doi: 10.1016/j.humpath.2008.06.028; PMid:18835620

Tripathi A, Hiscott P, Damato BE (2002). Malignant melanoma and massive retinal gliosis in phthisis bulbi. Eye;16:781-2. doi: 10.1038/sj.eye.6700217; PMid:12439677

Vemuganti GK, Jalali S, Honavar SG, Shekar GC (2001). Enucleation in a tertiary eye care centre in India: prevalence, current indications and clinicopathological correlation. Eye(Lond); 15:760-5. doi: 10.1038/eye.2001.245; PMid: 11826998

Völcker HE, Naumann GO (1976). Clinically unsuspected malignant melanomas of the posterior uvea (author's transl). Klin Monbl Augenheilkd;168(3):311-7. 